\title{
SISTEM INFORMASI SUGGESTION SYSTEM PADA PT ASTRA OTOPARTS TBK BERBASIS JAVA
}

\author{
Anwar Sanusi ${ }^{1}$, Rahnita Nuzulah ${ }^{2}$, Wahyu Nur Cholifah ${ }^{3}$ \\ Program Studi Teknik Informatika, Fakultas Teknik dan Ilmu Komputer, \\ Universitas Indraprasta PGRI \\ Jalan Raya Tengah No 80, Kelurahan Gedong, Pasar Rebo, Jakarta Timur \\ anwar.sansan48@gmail.com ${ }^{1}$, rahnita21@gmail.com² ${ }^{2}$,wncholifah.web@gmail.com ${ }^{3}$
}

\begin{abstract}
Abstrak
PT. Astra Otoparts, Tbk sangat mengandalkan perkembangan teknologi untuk mengembangkan bisnisnya, salah satunya melalui sumbangsih pemikiran dari para karyawan yang telah melahirkan inovasi yaitu suggestion system, yang sangat berpengaruh terhadap kemajuan perusahaan. Namun, sayangnya saat ini perusahaan tersebut masih mengalami kesulitan dalam hal proses dan pengelolaan data suggestion system, kendala yang dialami antara lain dalam pengolahan data suggestion system belum maksimal, dalam proses pengajuan dan pengolahan laporan yang kurang cepat dan akurat. Tujuan penelitian ini adalah untuk memberikan solusi masalah yang berkaitan dengan sistem informasi suggestion system pada PT. Astra Otoparts, Tbk Divisi Retail Shop And Drive. Metode penelitian yang digunakan dalam perancangan aplikasi ini adalah metode penelitian dan pengembangan dengan teknik kualitatif (grounded research). Pada metode ini data-data yang diberikan PT. Astra Otoparts, Tbk dikumpulkan dengan metode wawancara langsung kepada manajer HR perusahaan. Tidak hanya wawancara, juga dilakukan observasi di PT. Astra Otoparts, Tbk. Perancangan sistem informasi yang dibuat menggunakan bahasa pemrograman Java Script, antar muka aplikasi dikembangkan dari Framework Netbeans IDE 8.2 dan sebagai databasenya adalah MySQL. Hasil akhir yang dicapai pada sistem informasi suggestion system mempunyai kelebihan yaitu memudahkan user untuk melakukan aktivitas suggestion system dan pengolahan data yang digunakan dan memperoleh laporan informasi yang cepat dan akurat.
\end{abstract}

Kata Kunci : Sistem Informasi, Suggestion System, Java

\begin{abstract}
PT. Astra Otoparts, Tbk relies heavily on technological developments to develop its business, one of which is through the contribution of ideas from employees who have spawned innovations, namely the suggestion system, which greatly influences the progress of the company. However, unfortunately at this time the company is still experiencing difficulties in terms of processing and managing the data suggestion system, the obstacles experienced include the processing of the suggestion system data is not optimal, the submission process and report processing is not fast and accurate. The purpose of this study is to provide solutions to problems related to the suggestion system information system at PT. Astra Otoparts, Tbk Retail Shop And Drive Division. The research method used in designing this application is a research and development method with qualitative techniques (grounded research). In this method the data provided by PT. Astra Otoparts, Tbk were collected by direct interview method to the company's HR manager. Not only interviews, observations were also made at PT. Astra Otoparts, Tbk. The design of the information system is made using the Java Script programming language, the application interface is developed from the Netbeans IDE 8.2 Framework and the database is MySQL. The final result achieved in the suggestion system information system has the advantage that it makes it easier for users to carry out suggestion system activities and data processing used and obtain fast and accurate information reports.
\end{abstract}

Keyword : Information System, Suggestion System, Java

\section{PENDAHULUAN}

Teknologi Informasi (TI) telah berkembang sangat pesat pada saat ini. Teknologi Informasi merupakan penerapan teknologi yang digunakan untuk pengolahan data, memproses data, mendapatkan data, menyusun, menyimpan, manipulasi data dengan berbagai cara untuk menghasilkan informasi yang berkualitas, yaitu informasi yang relevan, akurat serta tepat waktu, juga bisa digunakan dalam keperluan pribadi, bisnis, dan pemerintahan, merupakan informasi yang 
cukup strategis untuk pengambilan sebuah keputusan. Selain itu juga teknologi informasi memiliki peran yang cukup penting didalam dunia bisnis dengan kemudahan yang disediakan. Bersamaan dengan perkembangan teknologi informasi yang saat ini semakin berkembang cukup pesat, pemanfaatan komputer pada saat ini merupakan salah satu kebutuhan setiap instansi. Kemajuan dalam suatu instansi bisa dilihat dari bagaimana cara memanfaatkan teknologi komputer sebagai alat bantu dalam menyelesaikan suatu masalah ataupun pekerjaan. Hal tersebut dapat membantu meningkatkan kinerja, alasan mengapa komputer lebih digunakan sebagai alat bantu dalam menyelesaikan suatu pekerjaan, karena pekerjaan yang dapat dilakukan menggunakan komputer memiliki kecepatan proses yang lebih dapat diandalkan (Muzakki et al, 2016).

Rumusan masalah penelitian ini adalah memecahkan permasalahan yang ada dalam perusahaan seperti proses yang belum tersistem, pengolahan data yang cukup memakan waktu dan pembuatan laporan yang masih kurang akurat.

Tujuan penelitian ini adalah agar proses aktivitas suggestion system menjadi lebih mudah, cepat, efisien terutama dalam pembuatan laporan dan pengolahan data yang diperlukan oleh admin untuk diserahkan kepada atasan.

\section{PENELITIAN RELEVAN}

Penelitian yang dilakukan oleh (Nugroho, 2014) yang berujudul Pembuatan Suggest-System Dalam Pengisian Kartu Rencana Studi Dengan Menggunakan Algoritma Genetika Studi Kasus STMIK Sinar Nusantara. Penelitian ini bertujuan untuk Mengimplementasikan algoritma Genetika dalam model Suggest System untuk pengisian Kartu Rencana Studi di STMIK Sinar Nusantara. Hasil penelitian dapat membantu/mengarahkan mahasiswa dalam memilih mata kuliah, pemilihan konsentrasi studi, dan masalah akademik lainnya.

Penelitian yang dilakukan oleh (Novrizal, 2020) yang berjudul Sistem Informasi Manajemen Aset Informasi Teknologi Pada 52 Group Berbasis Java. Penelitian ini bertujuan untuk Memudahkan pendataan asset IT pada perusahaan 52 Group. Hasil penelitian ini bermanfaat bagi perusahaan dalam pendataan asset IT sudah tidak dilakukan manual melainkan menggunakan system.

\section{METODE PENELITIAN}

Metode penelitian dapat memperlihatkan proses yang dikerjakan dengan cara mengumpulkan, mencatat, dan menganalisis informasi data yang ada. Metode penelitian yang digunakan peneliti adalah metode grounded research. (Nangka et al.,2021) "Grounded research adalah suatu metode penelitian yang mendasarkan diri kepada fakta yang menggunakan analisis perbandingan untuk mengadakan generalisasi teori, dan mengembangkan teori dimana pengumpulan data dan analisis data berjalan pada waktu yang bersamaan." Dalam grounded research, data merupakan sumber teori dan sebuah teori disebut grounded research karena teori tersebut berdasarkan data. Alasan memilih metode penelitian grounded research karena tahapan tahapanya dirasa sesuai dengan peneliatan yang dilakukan oleh peneliti. Dalam riset ini data merupakan sumber teori atau teori berdasarkan data secara empiris, bukan membangun teori secara deduktif logis, data empirik yang diperoleh secara sistematis.

\section{HASIL DAN PEMBAHASAN}

\section{Analisa Permasalahan}

1. Masih minimnya pemanfaatan teknologi dalam kegiatan pengajuan suggestion system.

2. Lembar pengajuan suggestion system masih menggunakan form manual yaitu menggunakan form excel.

3. Belum efektifnya pengolahan data karyawan dan suggestion system pada PT. Astra Otoparts, Tbk Divisi Retail Shop And Drive.

4. Karyawan tidak mengetahui reward yang didapatkan setelah mengajukan suggestion system. 


\section{Diagram Konteks}

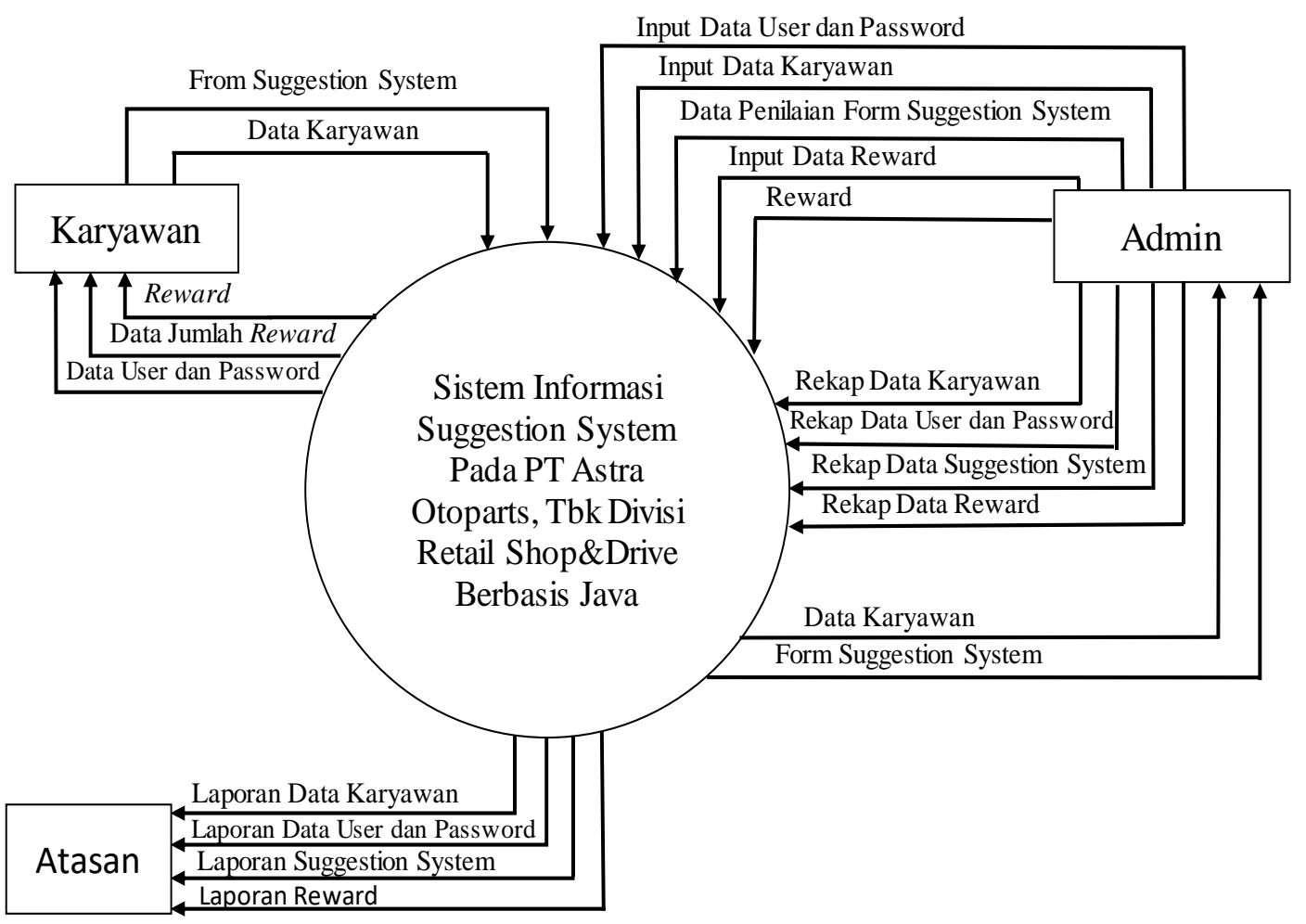

Gambar 1. Diagram Konteks

\section{ERD (Entity Relationship Diagram)}

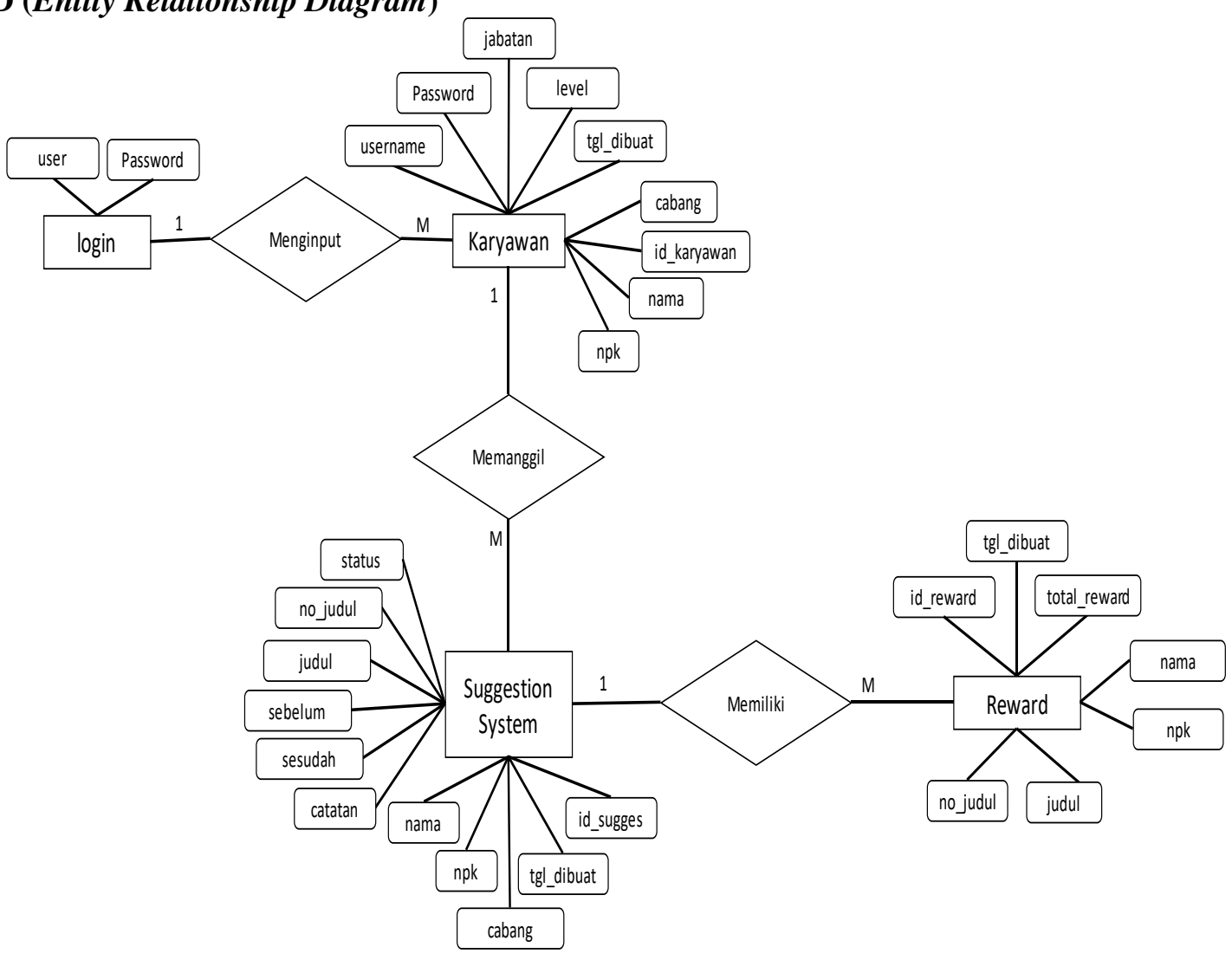

Gambar 2. ERD (Entity Relationship Diagram) 


\section{Tampilan Layar}

Berikut ini hasil perancangan Sistem Informasi Suggestion System pada PT. Astra Otoparts, Tbk Divisi Retail Shop And Drive Berbasis Java.

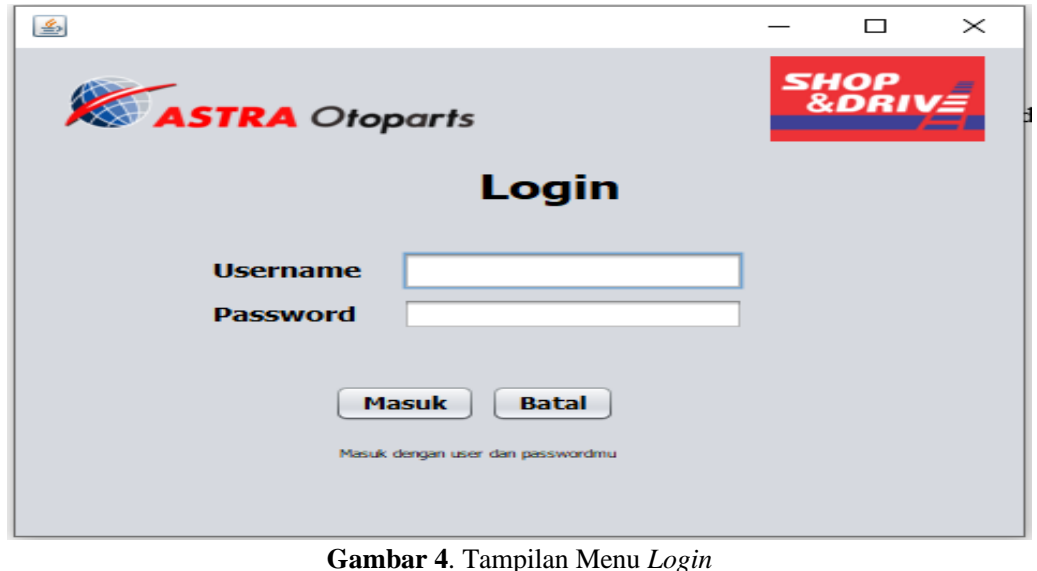

Gambar di atas merupakan tampilan menu login Untuk masuk ke dalam aplikasi ini, hal pertama yang harus dilakukan yaitu login, dengan mengisi username dan password yang sudah dibuatkan.

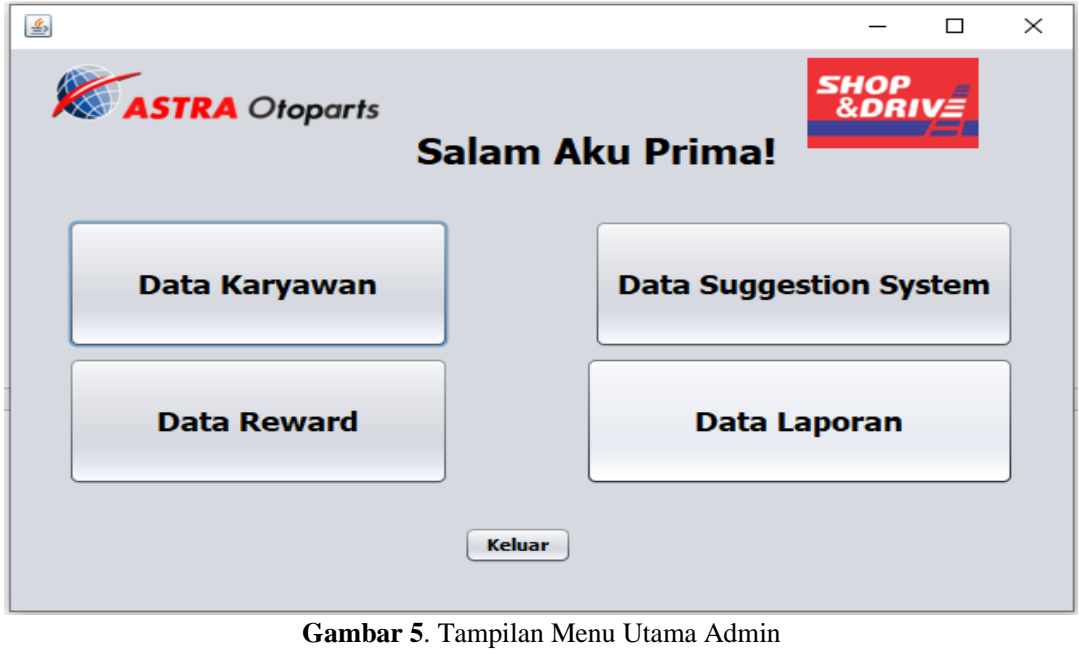

Gambar diatas merupakan tampilan menu utama admin.

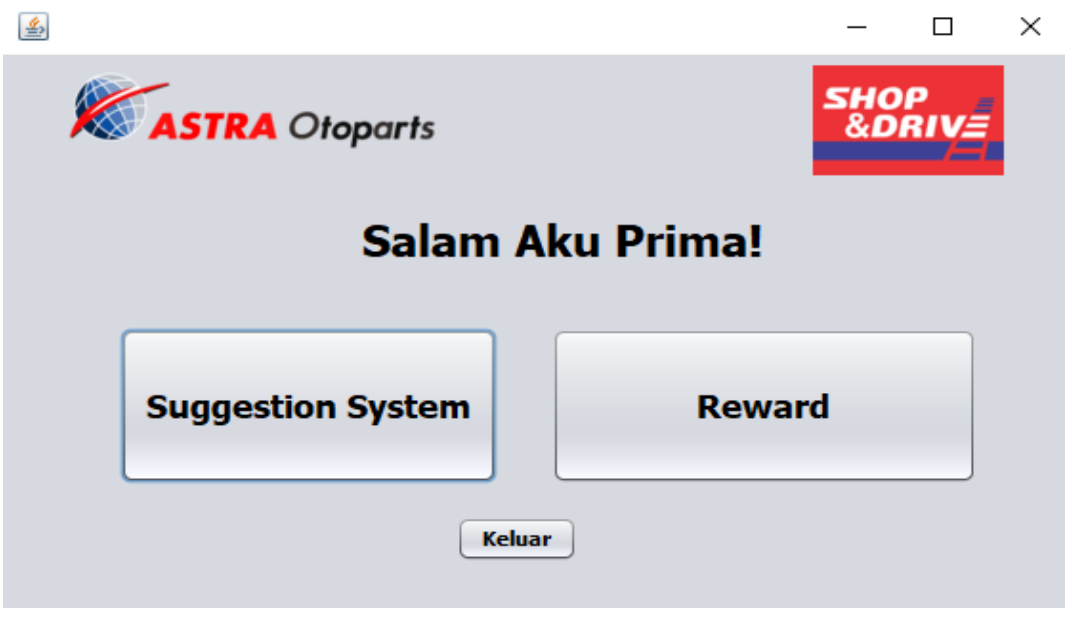

Gambar 6. Tampilan Menu Utama Karyawan 
Gambar diatas merupakan tampilan menu utama karyawan yang berfungsi untuk menampilkan menu yang dapat di akses.

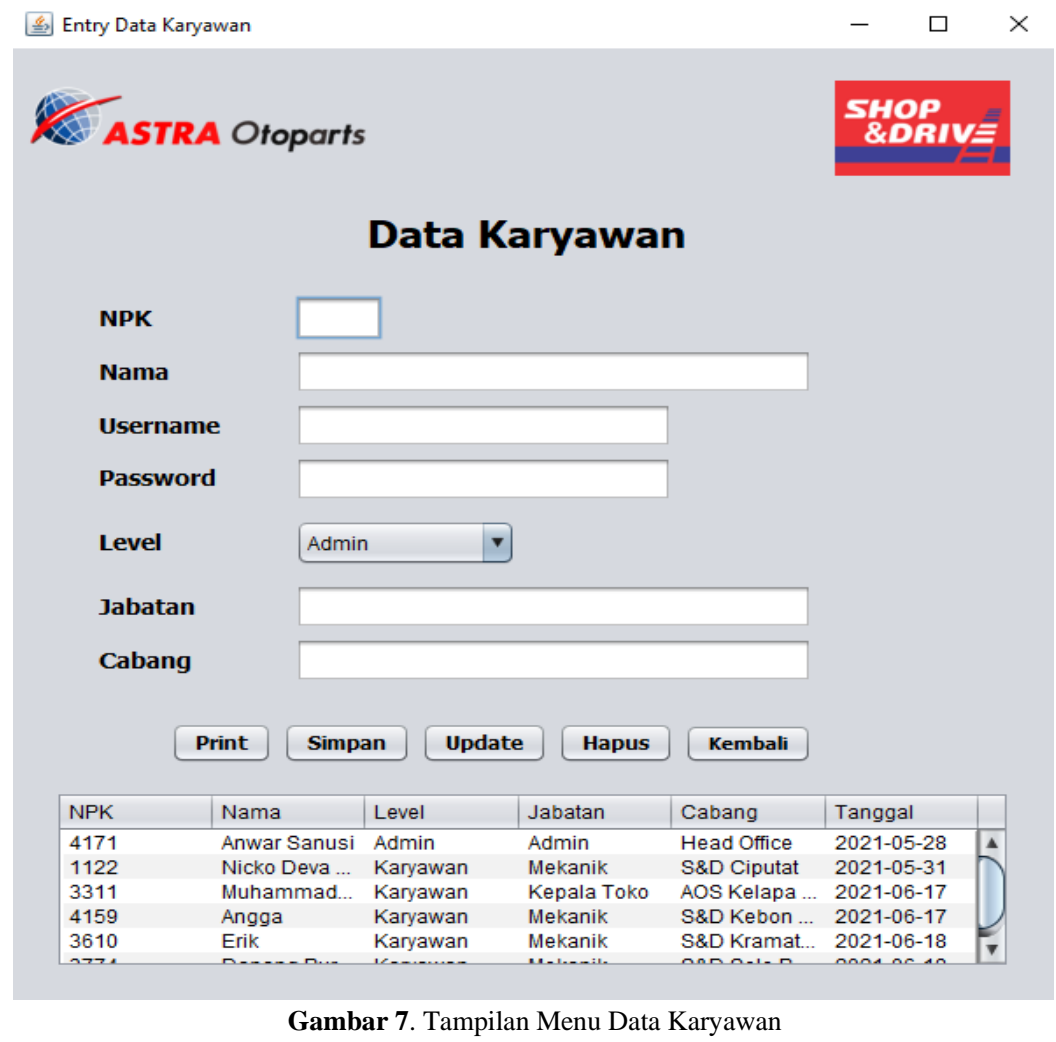

Gambar diatas merupakan tampilan menu data karyawan yang berfungsi sebagai pendataan data karyawan setiap adanya karyawan masuk atau keluar.

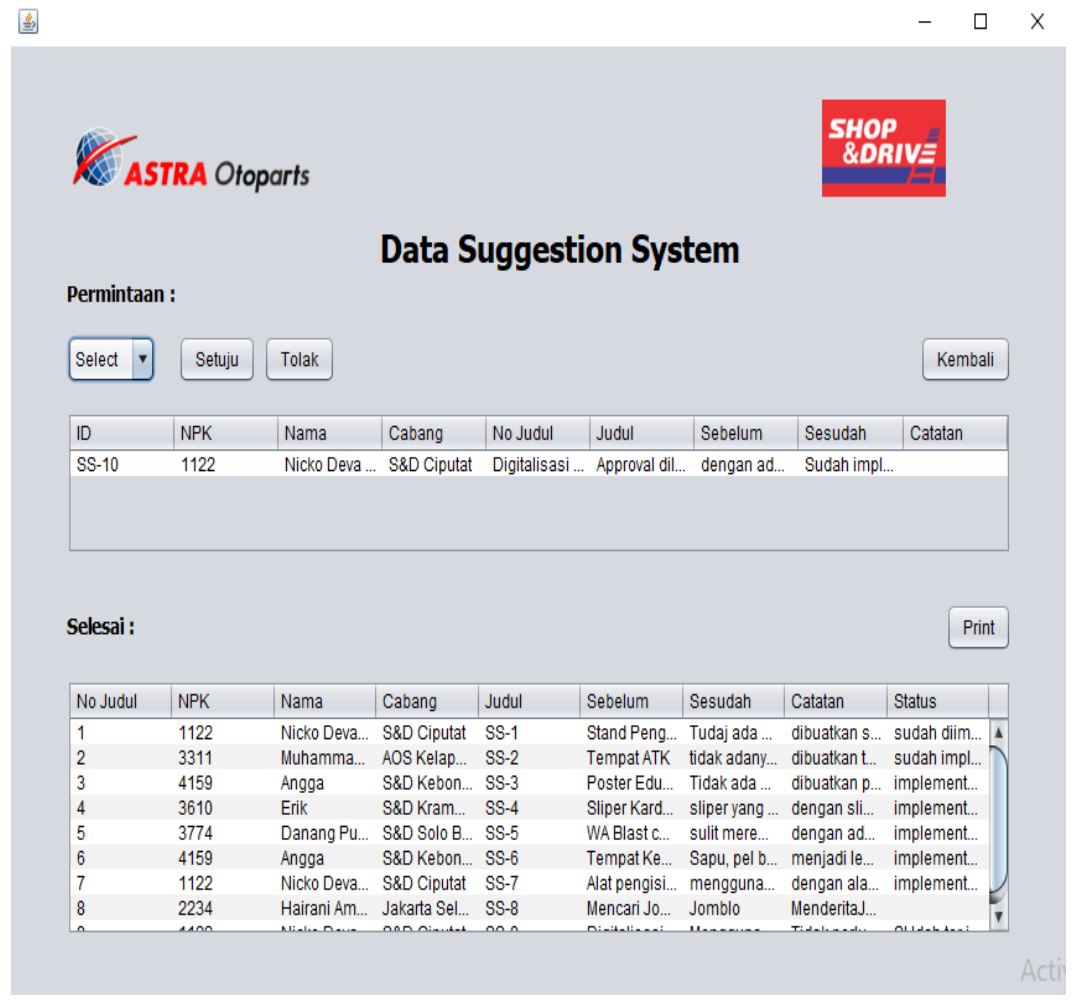

Gambar 8. Tampilan Menu Data Suggestion System Admin 


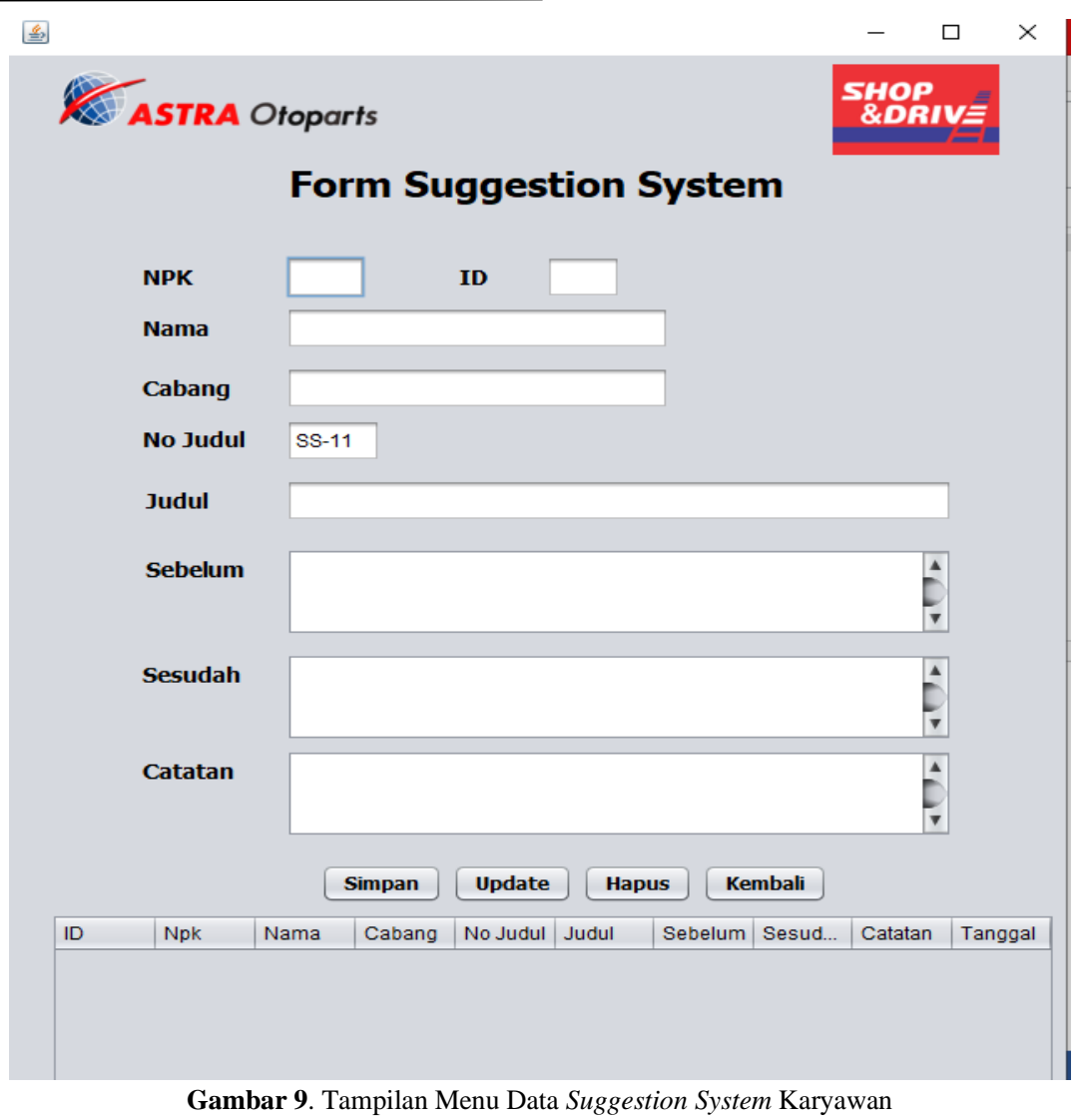

Gambar diatas merupakan tampilan Menu data suggestion system admin dan menu data suggestion system karyawan yang berfungsi sebgai tempat penginputan karyawan untuk mengajukan ide kepada admin dan untuk approve atau reject data suggestion system yang sudah diajukan oleh karyawan kepada admin.

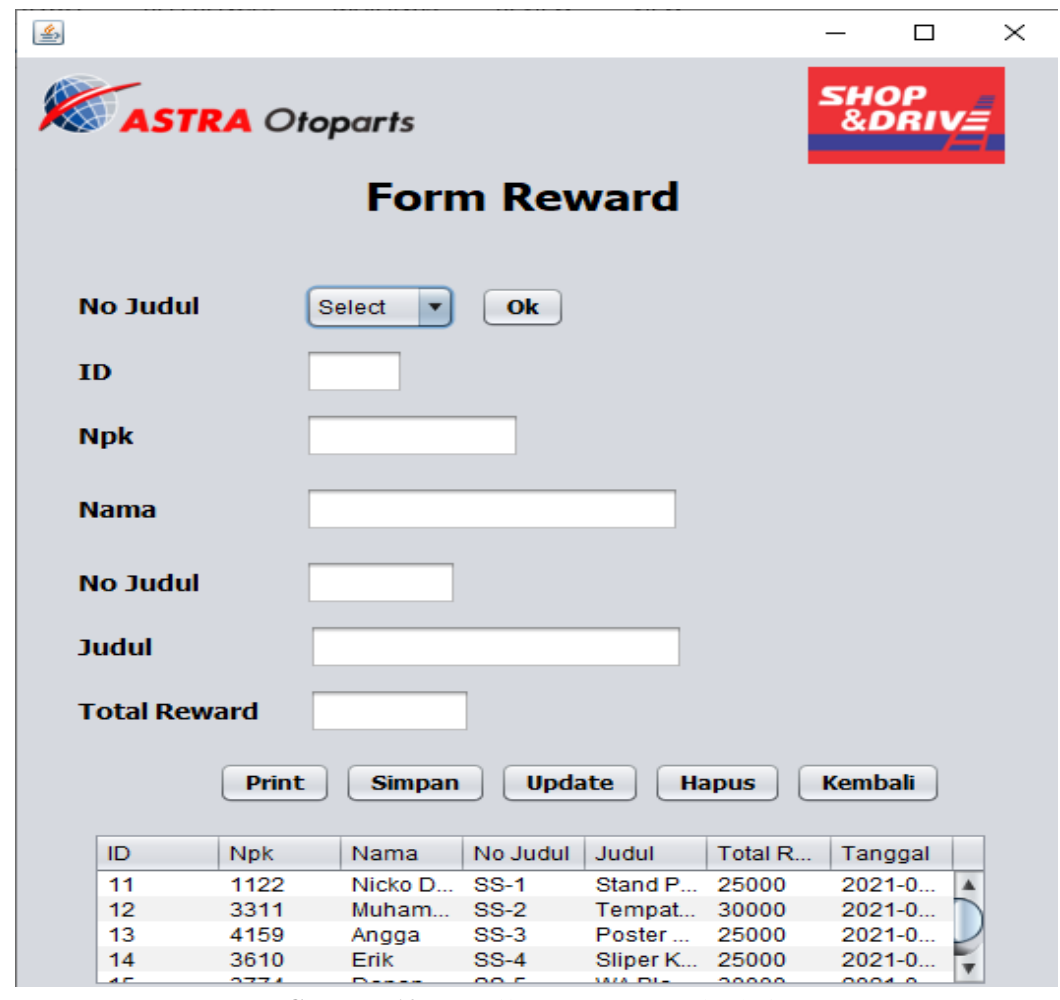

Gambar 10. Tampilan Menu Reward Admin 
Pada gambar diatas merupakan tampilan menu reward admin dan tampilan menu reward karyawan, untuk memberikan nominal reward pada data suggestion system yang sudah di approve oleh admin, setiap data suggestion system yang masuk berhak mendapatkan reward senilai Rp. 25.000 atau lebih tergantung dari kualitas suggestion system yang dikirim, dan sebagai tempat melihat rekapan reward yang di dapat oleh karyawan.

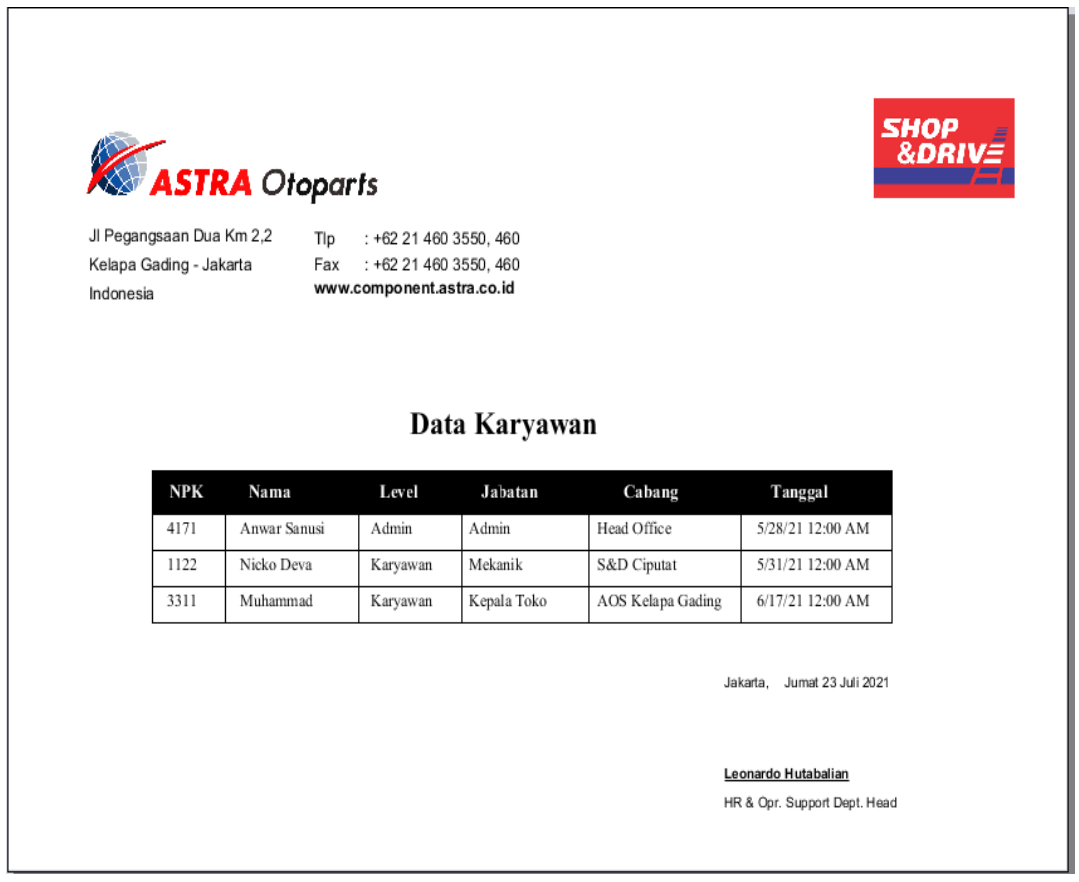

Gambar 11. Tampilan Laporan Data Karyawan

Gambar diatas merupakan tampilan hasil cetak laporan data karyawan.

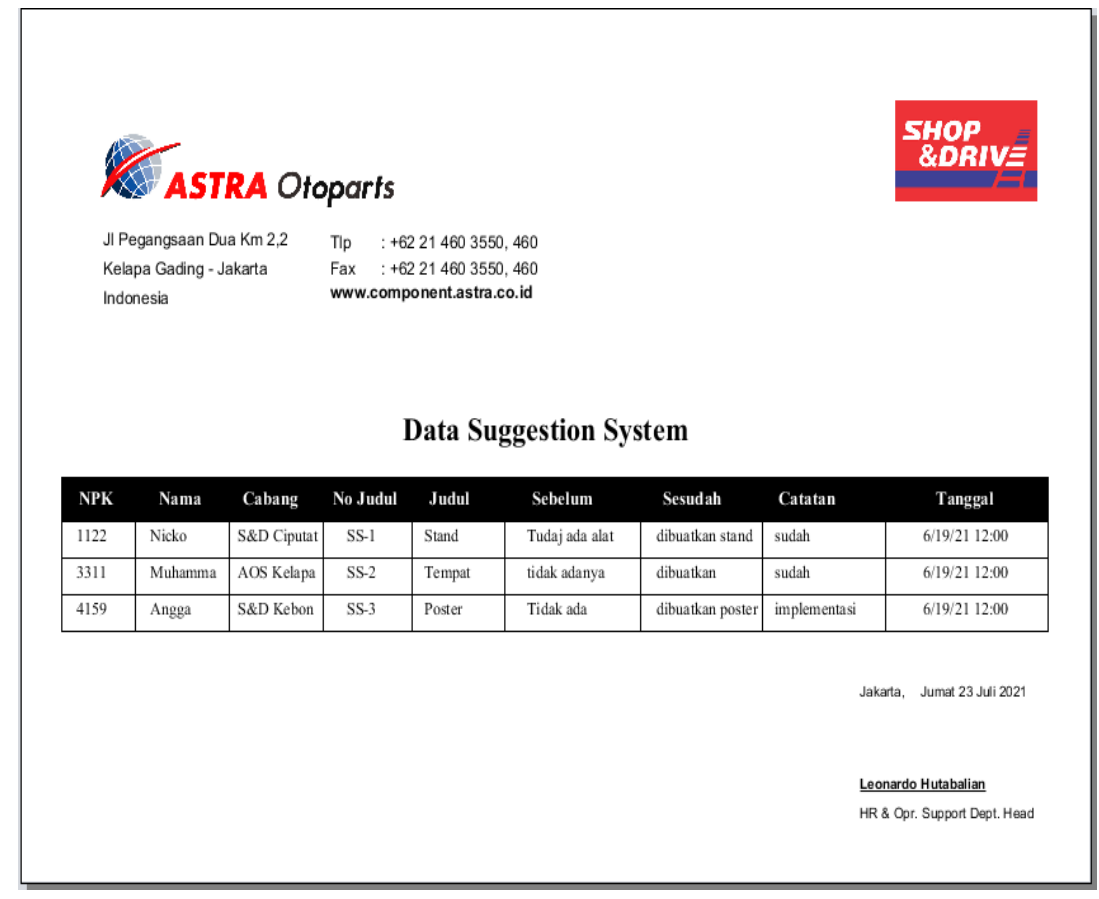

Gambar 12. Tampilan Laporan Data Suggestion System

Gambar diatas merupakan tampilan hasil cetak laporan data suggestion system. 


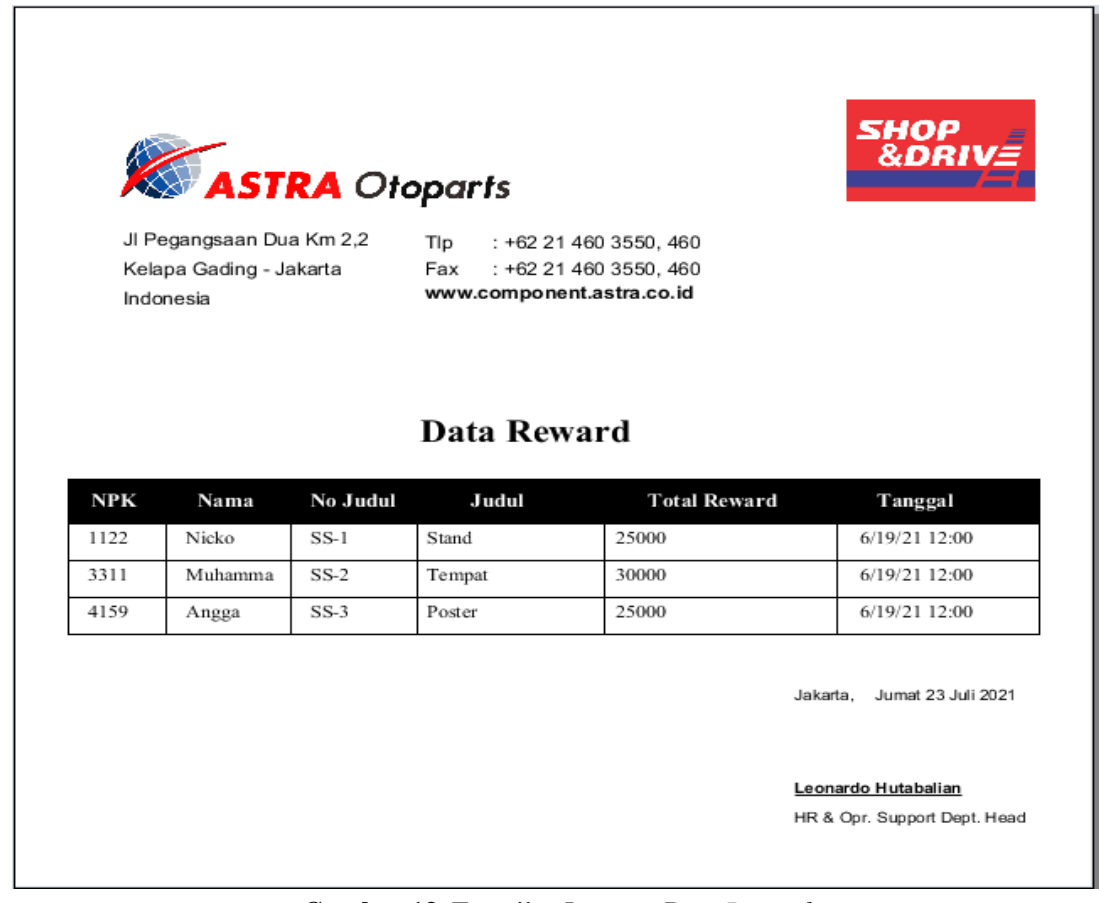

Gambar 13. Tampilan Laporan Data Reward

Gambar diatas merupakan tampilan hasil cetak laporan data reward.

\section{SIMPULAN}

Aplikasi sistem informasi suggestion system pada PT. Astra Otoparts, Tbk Divisi Retail Shop And Drive ini dirancang agar mudah dioperasikan oleh karyawan, ukuran file executable yang kecil serta rancangan tampilan yang tidak rumit sehingga memudahkan pemakai, sehingga dapat mempercepat proses penginputan dan pengolahan data karena sudah dibuat secara sistem.

\section{DAFTAR PUSTAKA}

Amirudin dan Dewi Masruroh, P. (2020). Implementasi Konsep Kaizen Dalam Meningkatkan. 18(1).

Asriyanik, A. (2016). Penilaian Keamanan Sistem Informasi Akademik Universitas Muhammadiyah Sukabumi Dengan Menggunakan ISO 27001. SANTIKA (Jurnal Ilmiah Sains Dan Teknologi), 6(2), 501-506.

Atmaji, L., \& Rahardjo, M. (2011). Pengaruh Stres Kerja dan Kepuasan Kerja terhadap Kinerja Perawat Studi pada Rumah Sakit Islam Sultan Agung Semarang. Universitas Diponegoro.

Hardiansyah, A. D., Nugrahaeni, D. C., Dewi, P., \& Kom, M. (2020). Perancangan Basis Data Sistem Informasi Perwira Tugas Belajar (Sipatubel) Pada Kementerian Pertahanan. Senamika, 1(2), 222-233. https://conference.upnvj.ac.id/index.php/senamika/article/view/529

I Putu Agus Eka Pratama. (2014). Sistem Informasi dan Implementasinya: Teori \& Konsep Sistem Informasi Disertasi Berbagai Contoh Praktiknya Menggunakan Perangkat Lunak Open Source. Informatika.

Indrajani, S. (2014). Database System Case Study All In One. Jakarta: PT. Elex Media Komputindo.

Manalu, E. S. M. (2019). Aplikasi Pengolahan Data Penjualan Dan Pembelian Serta Stok Barang Pada Kedaung Tabletop Plaza Palembang Berbasis Website. Politeknik Negeri Sriwijaya.

Muzakki, M. H., Susilo, H., \& Yuniarto, S. R. (2016). Pengaruh Penggunaan Teknologi Informasi Terhadap Kinerja Karyawan (Studi Pada Karyawan PT. TELKOM Pusat Divisi Regional V Surabaya). Jurnal Administrasi Bisnis (JAB), 39(2), 169-175.

Nangka, J., Barat, T., \& Selatan, J. (2021). Implementasi Firebase Realtime Database Pada Aplikasi Integrated Perpustakaan Smk Prestasi Prima. 283-288.

Pahlevi, S. M. (2013). Tujuh Langkah Praktis Pembangunan Basis Data. Elex Media Komputindo. 